Résumés des conférences et travaux

\title{
Histoire et philologie de la Scandinavie ancienne et médiévale
}

François-Xavier Dillmann

\section{(2) OpenEdition \\ Journals}

Édition électronique

URL : https://journals.openedition.org/ashp/2491

DOI : 10.4000/ashp.2491

ISSN : 1969-6310

Éditeur

Publications de l'École Pratique des Hautes Études

Édition imprimée

Date de publication : 1 septembre 2018

Pagination : 233-244

ISSN : 0766-0677

\section{Référence électronique}

François-Xavier Dillmann, « Histoire et philologie de la Scandinavie ancienne et médiévale », Annuaire de l'École pratique des hautes études (EPHE), Section des sciences historiques et philologiques [En ligne], 149 | 2018, mis en ligne le 10 juillet 2018, consulté le 03 août 2021. URL : http:// journals.openedition.org/ashp/2491; DOI : https://doi.org/10.4000/ashp.2491 


\title{
HISTOIRE ET PHILOLOGIE DE LA SCANDINAVIE ANCIENNE ET MÉDIÉVALE
}

\author{
Directeur d'études : M. François-Xavier Dillmann, \\ correspondant de l'Institut
}

Programme de l'année 2016-2017 : I. Recherches sur l’Óláfs saga ins helga de Snorri Sturluson. - II. Lecture et explication de textes norrois sur la guerre dans la Scandinavie ancienne et médiévale. - III. Études sur la bataille de Stiklestad.

Dans le prolongement des conférences de l'an dernier, on s'est proposé cette année d'étudier plusieurs questions concernant la bataille qui se déroula à Stiklestad, dans la province du Trøndelag (Norvège), au cours de l'été 1030. Après avoir rappelé que ce combat mit aux prises le roi Olaf Fils Harald (v.isl. Óláfr Haraldsson) qui, à la tête de forces recrutées en grande partie en Suède, tentait de reprendre possession de son pouvoir, et un vaste rassemblement de paysans et de chefs locaux, originaires de la plupart des provinces du pays, l'importance de cette bataille dans l'histoire politique et religieuse de la Norvège médiévale a été soulignée : ce fut en effet au cours de ce combat qu'Olaf Fils Harald trouva la mort, événement qui fut suivi, un an plus tard environ, de la proclamation de la sainteté du défunt, lors de la translatio de sa dépouille dans l'église Saint-Clément, à Nidaros (l'actuelle métropole de Trondheim).

L'examen de l'ensemble des sources écrites - tant latines que norroises - qui nous ont conservé le souvenir de cette bataille a montré que seule la Saga Óláfs konungs hins helga (ou Histoire du roi Olaf le Saint), œuvre qui est généralement attribuée à l'historien et poète islandais Snorri Sturluson ${ }^{1}$, en offrait un récit un tant soit peu détaillé, et le fait a été expliqué par la connaissance, beaucoup plus étendue que celle de ses prédécesseurs immédiats, que son auteur possédait des strophes scaldiques qui furent composées dans les années ou les décennies qui suivirent la mort d'Olaf Fils Harald. Parmi ces dernières figure au premier chef l'Erfidrápa Óláfs helga (ou Poème funèbre d'Olaf le Saint) du scalde Sigvat Fils Thord (v.isl. Sigvatr Pórðarson) qui, pour une large part, décrit la dernière bataille que livra le futur saint Olaf.

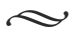

Les conférences des trois premiers mois ont été entièrement consacrées à l'étude de l'une des questions les plus débattues qui soit au sein de l'historiographie du roi de Norvège Olaf Fils Harald et qui concerne un événement qui se serait produit pendant l'été de l'année 1030 : selon plusieurs sources norroises - deux strophes scaldiques, composées pour l'une peu après la disparition d'Olaf et pour l'autre au milieu du $\mathrm{XII}^{\mathrm{e}}$ siècle, et deux ouvrages historiques de la première moitié du siècle suivant -, l'obscurité serait tombée subitement au cours de la bataille de Stiklestad.

1. Rappelons que la Saga Óláfs konungs hins helga, qui doit avoir été composée vers 1225-1230, fut ensuite insérée, avec quelques ajustements, dans le recueil intitulé la Heimskringla (ou Histoire des rois de Norvège), dont elle constitue la partie centrale. 
Depuis la publication de l'étude de l'astronome norvégien Christopher Hansteen qui était intitulée Om det rette Aar og Dagen, da Slaget ved Stikklestad blev holdet ${ }^{2}$, la discussion a porté principalement sur les points suivants : une éclipse du soleil s'est-elle réellement manifestée dans la province du Trøndelag, en Norvège, le jour du combat qui vit la mort d'Olaf Fils Harald et la défaite de ses forces? Ou s'agit-il plutôt d'une légende qui aurait pris naissance après les événements de l'été 1030 et qui, d'inspiration hagiographique, aurait eu pour dessein de modeler, en recourant au procédé de syncrisis, la fin tragique d'Olaf Fils Harald sur les récits évangéliques de la Passio de Jésus? Dès lors, cette légende fut-elle créée de toutes pièces? Ou trouvet-elle son origine dans la connaissance que l'on avait pu conserver de l'éclipse solaire qui, le 31 août de l'année 1030, obscurcit le ciel du Trøndelag, en particulier dans la vallée du Verdalen où se situe Stiklestad ${ }^{3}$, en sorte que la description d'un phénomène naturel aurait été insérée dans le récit d'une bataille qui se serait déroulée à une autre date? Par exemple le 29 juillet de la même année, jour qui, au moins depuis le milieu du $\mathrm{XI}^{\mathrm{e}}$ siècle, est celui de la célébration de la Saint-Olaf?

Selon les réponses qui ont été apportées à ces questions, des conséquences d'une grande portée historique ont pu être tirées : elles concernent non seulement la date de la dernière bataille d'Olaf Fils Harald, mais la vénération de ce personnage qui, si l'on en croit la tradition norroise, fut proclamé saint peu après l'inventio de ses reliques dans la bourgade de Nidaros, un an environ après sa mort.

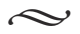

C'est dans une strophe que le scalde Sigvat Fils Thord a dû composer au cours de la décennie qui suivit la mort d'Olaf Fils Harad que figure, pour la première fois, l'évocation d'un phénomène astronomique de grande ampleur qui se serait produit le jour où le roi de Norvège livra son ultime bataille. Cette très belle strophe est parvenue jusqu'à nous par la tradition manuscrite de la Saga Óláfs konungs hins helga (ou Grande Histoire du roi Olaf le Saint) et par la version de cet ouvrage qui fut insérée dans le recueil de la Heimskringla. Elle est citée au chapitre CCXXv de la première ${ }^{4}$, qui correspond au chapitre CCXXVII de la seconde (l'Óláfs saga ins helga ou Histoire du roi Olaf le Saint ${ }^{5}$ ).

2. Dans Samlinger til Det Norske Folks Sprog og Historie, I, Christiania, 1833, p. 452-477.

3. Christopher Hansteen, « Om det rette Aar og Dagen da Slaget ved Stikklestad blev holdet », art. cit., p. 462-466; Halvdan Koht, « Solmyrke i Stiklestad-slage », dans Olsok 1924. Aarbok utgjevi av Norrønafelaget Bragr, Bergen, 1924, p. 30-32; Joh. D. Landmark, Solmørket over Stiklestad. En sagnhistorisk undersøkelse, Trondheim, Det Kgl. Norske Videnskabers Selskab (Skrifter 1931, 3), 1931, p. 29-30; Porkell Porkelsson, « Stiklarstaðaorusta og sólmyrkvinn », Skirnir, CVII, 1933, p. 147; Bjarni Aðalbjarnarson, « Formáli », dans Snorri Sturluson, Heimskringla, II, 1945, p. XCIII ; A. W. Brøgger, Stiklestadslaget, Oslo (Avhandlinger utgitt av Det Norske Videnskaps-Akademi i Oslo. II. Hist.-Filos. Klasse, 1946, II), 1946, p. 15.

4. Saga Óláfs konungs hins helga. Den store saga om Olav den hellige. Efter pergamenthåndskrift i Kungliga Biblioteket i Stockholm Nr. $24^{\text {to }}$ med varianter fra andre håndskrifter. Utgitt for Kjeldeskriftfondet av Oscar Albert Johnsen og Jón Helgason, I, Oslo (Norsk Historisk Kjeldeskrift-Institutt), 1941, p. 572 .

5. Snorri Sturluson, Heimskringla, II. Bjarni Aðalbjarnarson gaf út, Reykjavik, Hið íslenzka fornritafélag (Íslenzk fornrit, XXVII), p. 382. 
Souvent considérée comme faisant partie de l'Erfidrápa Óláfs helga (ou Poème funèbre d'Olaf le Saint ${ }^{6}$ ), que le scalde pourrait avoir composée au début du règne (1035-10477) de Magnus Fils Olaf (v.isl. Magnús Óláfsson), la strophe sur l'éclipse solaire peut tout aussi bien avoir vu le jour indépendamment de ce poème, dès que Sigvat Fils Thord, de retour dans le Trøndelag après un pèlerinage à Rome, aura appris la nouvelle de la bataille de Stiklestad : l'hypothèse en a été avancée, mais rien ne permet véritablement de trancher entre ces deux possibilités ${ }^{8}$.

Composée dans le mètre rigoureux qui est celui du dróttkvaett, cette strophe illustre toute la virtuosité du scalde islandais, qui s'est efforcé de respecter l'emploi des allitérations dans chacun des quatre longs vers et l'alternance des assonances dans les vers pairs et impairs, comme cela a été montré au cours de l'une des conférences ${ }^{9}$ :

Undr láta pat ýtar

eigi smátt, es máttit

skæ-Njǫrðungum skorðu

skýlauss rǫðull hlýja.

Drjúg varð á pví doegri,

dagr náđit lit fọgrum,

orrostu frák austan

atburð, konungs furða.

L'ordre des mots et la disposition des phrases au sein des deux parties de cette strophe en dróttkvaett ne soulèvent pas de grandes difficultés, si bien que la construction proposée par Finnur Jónsson ${ }^{10}$, à la suite de Konráð Gíslason ${ }^{11}$, a le plus souvent été retenue ${ }^{12}$, ainsi par Bjarni Aðalbjarnarson dans l'annotation de son édition de la Heimskringla (II, éd. cit., p. 382-383) :

6. Finnur Jónsson, dans Den norsk-islandske Skjaldedigtning. Udgiven af Kommissionen for Det Arnamagnæanske Legat ved Finnur Jónsson, A. Tekst efter Håndskrifterne, I, Copenhague, Kristiania, Gyldendalske Boghandel, Nordisk Forlag, 1912 p. 261, cf. ibid., B, I, p. 242; Ernst A. Kock, Den norsk-isländska skaldeditkningen, I, Lund, Gleerups, 1946, p. 125; Judith Jesch, « Sigvatr Pórðarson, Erfidrápa Óláfs helga », dans Poetry from the Kings'Sagas 1: From Mythical Times to c. 1035. Part 2. Edited by Diana Whaley, Turnhout, Brepols (Skaldic Poetry of the Scandinavian Middle Ages, I, 2), 2012, p. 682-683. - Selon le classement qui fut établi par Finnur Jónsson (ibid.) et qui a été retenu par les autres éditeurs, ce serait la strophe Xv de ce poème.

7. Cf. Judith Jesch, dans Poetry from the Kings'Sagas 1, éd. cit., p. 664-665. - L'opinion qui a longtemps prévalu voulait que ce poème ait été composé peu de temps avant la mort du scalde vers 1044/1045, cf. p. ex. Hallvard Lie, «Sigvatr Pórðarson », dans Kulturhistorisk leksikon for nordisk middelalder fra vikingetid til reformationstid, XV, Copenhague, Rosenkilde og Bagger, 1970, col. 237; E. O. G. Turville-Petre, Scaldic Poetry, Oxford, Clarendon, 1976, p. 83.

8. Bjarni Aðalbjarnarson, Heimskringla, II, éd. cit., p. XCIV.

9. La citation de la strophe est extraite de l'édition procurée par Bjarni Aðalbjarnarson (Heimskringla, II, éd. cit., p. 382), qui suit l'édition établie par Finnur Jónssson, Skjaldedigtning, B, I, éd. cit., p. 242.

10. Heimskringla. Nóregs konunga sogur af Snorri Sturluson, IV : Fortolkning til versene. Udgivne for Samfund til Udgivelse af Gammel Nordisk Litteratur, XXIII, Copenhague, 1901, p. 169; Skjaldedigtning, B, I, éd. cit., p. 242.

11. Udvalg af Oldnordiske Skjaldekvad, med Anmærkninger ved Konráð Gíslason. Udgivet af Kommissionen for Det Arnamagnæanske Legat, Copenhague, Gyldendalske Boghandel, 1892, p. 40.

12. E. A. Kock et R. Meissner, Skaldisches Lesebuch. Teil I : Text, Halle (Saale), Max Niemeyer Verlag (Rheinische Beiträge und Hülfsbücher zur germanischen Philologie und Volkskunde, XVII), 1931, p. 32; E. A. Kock, Den norsk-isländska skaldeditkningen, éd. cit., p. 125 ; E. O. G. Turville-Petre, 
Ýtar láta pat eigi smátt undr, es skýlauss rǫðull máttit hlýja skorðu skæ-Njǫrðungum. Drjúg varð furða konungs á pví dœgri; dagr náđit fọgrum lit; frák atburð orrostu austan.

Comme cela a été rappelé par le directeur d'études, la seule proposition divergente, qui fut émise par le philologue suédois Otto von Friesen ${ }^{13}$, concerne simplement la seconde partie de la strophe : et elle apparaît beaucoup trop contournée pour pouvoir emporter l'adhésion ${ }^{14}$.

L'examen a ensuite porté sur la kenning qui a été insérée dans la première partie de cette strophe et qui est constituée par le vers 3 (skce-Njorðungum skorðu), dans lequel le composé skce-Njorðungar est au datif : attesté uniquement au pluriel (et toujours dans des composés ${ }^{15}$ ), l'élément Njorðungar (ou njorðungar) doit être une formation sur le nom du dieu Njorðr ou sur la racine de ce dernier ${ }^{16}$; à ce titre, elle est employée dans des kenningar désignant les hommes, comme le montre la citation de la première partie de cette strophe dans un fragment de l'Edda de Snorri Sturluson ${ }^{17}$. La périphrase métaphorique skorðu skcer (littéralement : " cheval du tin ») désigne quant à elle le navire lui-même : le féminin skorða signifie proprement « étai de soutien [du navire en construction ${ }^{18}$ ] » en désignant l'ensemble des « accores » ou des « tins »; les Njorðungar d'un tel navire sont les membres de l'équipage et, partant, les hommes ${ }^{19}$. Il s'agit manifestement d'une kenning d'un type habituel pour désigner

Scaldic Poetry, éd. cit., p. 85; Bergljót S. Kristjánsdóttir, dans Snorri Sturluson, Heimskringla, II, Reykjavik, Mál og menning, 1991, p. 532; J. Jesch, « Sigvatr Pórðarson, Erfidrápa Óláfs helga 15 », éd. cit., p. 682.

13. Sighvat skald och solförmörkelsen år 1030, Upsal (Språkvetenskapliga Sällskapets i Uppsala Förhandlingar 1922-1924, Uppsala Universitets Årsskrift 1922-1924, Bilag A), 1924, p. 6-7 : selon cet auteur, le second helmingr (ou demi-strophe) comprendrait d'abord la phrase Drjúg varð furða konungs (limitée à ces quatre mots), tandis que la phrase dagr nádit fogrum lit serait une proposition relative (sans particule initiale) qui serait reliée au syntagme á pví dogri, lequel introduirait lui-même la phrase frák atburð orrostu austan, et la traduction de cette demi-strophe serait dès lors : « Ja, stort var det varsel om konungen, som inträffade; samma dag, som dagsljuset ej fick sin (vanliga) klarhet, erfor jag i västerväg stridens förlopp. »

14. Reprise par H. Koht, « Solmyrke i Stiklestad-slage », art. cit., p. 37) puis par J. D. Landmark, Solmørket over Stiklestad, op. cit., p. 15 sq. et passim, elle a été réfutée avec des arguments entièrement convaincants par Ernst A. Kock, Notationes Norrœnœ. Anteckningar till Edda och skaldediktning. Femte delen, Lund, Leipzig (Lunds Universitets Årsskrift. N.F. Avd. 1. Bd. 21. Nr. 1), 1925, § 662, p. 32-33.

15. Finnur Jónsson, Lexicon poeticum antiquce linguce Septentrionalis. Ordbog over det norsk-islandske skjaldesprog. Oprindelig forfattet af Sveinbjörn Egilsson. Forøget og påny udgivet for det Kongelige Nordiske Oldskriftselskab. 2. udgave ved Finnur Jónsson, Copenhague, 1931, p. 429.

16. Hjalmar Falk, « Ordstudier I, 3. Nọrungar og njorðungar », Arkiv för nordisk filologi, XLIV, 1928, p. 319-321; Finnur Jónsson, Lexicon poeticum, op. cit., p. 429; Ásgeir Blöndal Magnússon, Íslensk orðsifjabók, s.1. [Reykjavik], Orðabók Háskólans, 1989, p. 671, s.v. -njorðung(u)r.

17. Jón Sigurðsson éd., Edda Snorra Sturlusonar. Edda Snorronis Sturlaei. Tomus Secundus. Copenhague (Sumptibus Legati Arnamagnæani), 1852, p. 497; Edda Snorra Sturlusonar. Codex Wormianus AM 242, fol. Udgiven af Kommission for Det Arnamagnæanske Legat [ved Finnur Jónsson], Copenhague, Kristiania, Gyldendalske Boghandel, Nordisk Forlag, 1924, p. 105.

18. Johan Fritzner, Ordbog over Det gamle norske Sprog. Omarbeidet, forøget og forbedret Udgave, Kristiania, III, 1896, p. 369-370; Hjalmar Falk, Altnordisches Seewesen, Heidelberg, Carl Winter's Universitätsbuchhandlung (= Sonderdruck aus Wörter und Sachen, IV. Band), 1912, p. 30-31; Finnur Jónsson, Lexicon poeticum, op. cit., p. 511.

19. Finnur Jónsson, dans Heimskringla, IV, 1901, p. 169; Finnur Jónsson, Lexicon poeticum, op. cit., p. 517; R. Meissner, Skaldisches Lesebuch, II : Wörterbuch, 1931, p. 160; Bjarni Aðalbjarnarson, 
les hommes en général ${ }^{20}$, plutôt que les navigateurs en particulier ${ }^{21}$. C'est néanmoins en se fondant sur cette acception précise que l'hypothèse a été avancée selon laquelle, en choisissant (ou en forgeant lui-même) la présente kenning, le scalde aurait visé ses compatriotes qui, après avoir traversé la mer, seraient entrés au service du roi Olaf Fils Harald ${ }^{22}$, en sorte que la participation des Islandais à la bataille de Stiklestad aurait été « relativement importante ${ }^{23}$ ». En dépit de l'ingéniosité de plusieurs des arguments développés en ce $\operatorname{sens}^{24}$, il ne fait guère de doute que l'expression doit désigner de préférence les hommes considérés dans leur ensemble, tant il est vrai que l'évocation par le scalde des effets d'un phénomène astronomique doit avoir une portée générale plutôt que s'appliquer à un seul groupe de guerriers au sein de l'un des deux camps en présence sur le champ de bataille ${ }^{25}$.

Disposée autour de cette remarquable kenning, la première partie de la strophe nous apprend que, lors même qu'il était « serein (skýlauss, littéralement : sans nuages) », qu'il brillait dans un ciel dégagé, l'astre solaire (roðull) ne put réchauffer (hlýja) les « hommes (ska-Njorðungar skorðu) », et que cela fut considéré comme n'étant pas une « mince merveille (undr eigi smátt, littéralement : merveille non petite) »; il s'agit naturellement d'une litote pour exprimer le fait que l'on estima qu'il s'agissait là d'un grand prodige.

Dans la seconde partie de la strophe, au vers 6, Sigvat déclare que « belle couleur, le jour n'obtint pas (dagr nádit lit fogrum) », en employant à nouveau une litote afin de mettre en valeur l'obscurité qui se fit au cours de la bataille. Le scalde considère que ce fut un «puissant présage (drjúg furða) » qui se manifesta pour le roi « ce jour-là (á pví dogri) ». Et son propos s'achève sur cette phrase : Frák atburð orrostu

Heimskringla, II, éd. cit., p. 383; Judith Jesch, « Sigvatr Pórðarson, Erfidrápa Óláfs helga 15 », éd. cit., p. 682.

20. Ernst A. Kock, Notationes Norronce, op. cit., §662.

21. Otto von Friesen, Sighvat skald och solförmörkelsen, op. cit., p. 5, qui traduit cette kenning par sjömännen, cf. son commentaire p. 7-8, avec la glose sjömän, sjökrigare.

22. Barði Guðmundsson, « Omkring Stiklestadslaget », [Svensk] Historisk tidskrift, LXXII, 1952, p. 154157.

23. Ibid., p. 154 : en forholdsvis stor deltagelse av islendinger $i$ slaget.

24. Ibid., p. 154-157, mais il est pour le moins incertain que la description donnée par Adam de Brême (Gesta Hammaburgensis ecclesiae Pontificum, II, LXI, éd. Bernhard Schmeidler, Hanovre, Leipzig [Scriptores Rerum Germanicarum in usum scholarum. Ex Monumentis Germaniae Historicis], 1917, p. 121, cf. éd. Werner Trillmich, Darmstadt, Wissenschaftliche Buchgesellschaft [Ausgewählte Quellen zur deutschen Geschichte des Mittelalters, XI], 1961, p. 300) des forces du roi Olaf Fils Harald à son retour d'exil fasse réellement mention d'Islandais (comme le voulait Barði Guðmundsson, art. cit. 1952, p. 156) : l'ensemble des manuscrits présentent ici la leçon de ... populis insularum, qui paraît beaucoup plus acceptable que la leçon du seul manuscrit $\mathrm{A}^{1}:$ de ... populis islanorum, cf. Tore Nyberg, «Stad, skrift och stift. Några historiska inledningsfrågor », dans Adam av Bremen, Historien om Hamburgstiftet och dess biskopar. Översatt av Emanuel Svenberg. Kommenterad av Carl Fredrik Hallencreutz et al., Stockholm, Propius (Skrifter utgivna av Samfundet Pro fide et christianismo, VI), 1984 , p. 327.

25. On observera que, dans sa première étude sur le sujet (« Dagsetning Stiklastaðaorustu », Andvari, LXII, 1937, p. 108), Barði Guðmundsson rendait cette kenning par le mot hermenn (guerriers), sans autre commentaire. 
austan, dans laquelle l'adverbe austan peut être interprété de plusieurs manières, en signifiant :

a) « de l'Est », « en provenance de l'Est », en accord avec la signification obvie de cette forme adverbiale, ce qui pourrait laisser penser que Sigvat se serait trouvé en Europe occidentale lorsqu'il apprit la nouvelle de l'événement ${ }^{26}$;

b) « à l'Est », l'adverbe austan étant pris ici au sens de la locution adverbiale fyrir austan, et l'expression pourrait désigner l'Europe orientale, mais aussi la mer Baltique ou la Suède, et elle s'expliquerait par le fait que le scalde avait entrepris dans les années 1029-1030 des voyages en direction du sud et de l'est ${ }^{27}$;

c) « à l'Est », entendons : « en Norvège », austan équivalant ici à austr, comme le proposait Finnur Jónsson ${ }^{28}$, en accord avec les emplois proprement islandais de cet adverbe et des composés auxquels il a donné naissance (par exemple l'appellatif aust$m a ð r$, qui désigne notamment un Norvégien ${ }^{29}$ ), et aussi d'un emploi semblable dans une autre strophe de Sigvat $^{30}$.

Dans cette dernière hypothèse, que nous avons retenue de préférence, le scalde aura déclaré que ce fut la bataille elle-même qui se déroula " à l'Est ", " en Norvège $^{31} »$, l'adverbe se rapportant ici au mot orrosta (ou au syntagme nominal atburðr orrostu, voir ci-dessous), mais on ne peut exclure l'interprétation concurrente : l'adverbe austan se rapporterait plutôt à la forme verbale frák («j'appris / j'ai appris »), et le scalde indiquerait alors que ce fut « de l'Est ${ }^{32} »$, « de Norvège », qu'il reçut la nouvelle de cet événement, et ce quel que fût le lieu où il s'était trouvé à ce moment-là.

Si l'adverbe austan est équivoque, la signification des autres termes de la dernière phrase de cette strophe ne fait pas difficulté, et cependant l'un d'entre eux - le substantif atburðr - a souvent été traduit de manière fautive ou à tout le moins trop libre, comme le montrent ces quelques exemples : «I öster sporde / jag, hur drabbningen gått till ${ }^{33} »$, « of the battle / I heard news from parts eastern ${ }^{34}$ », " I have heard the course of the battle from the east ${ }^{35} »$. Objet direct du verbe fregna, qui est employé ici sous l'acception « apprendre », le masculin atburðr signifie d'abord « événement, incident ${ }^{36}$ », en accord avec sa formation sur le verbe bera $(s k) a t^{37}$.

26. Bjarni Aðalbjarnarson, Heimskringla, II, éd. cit., p. 383 ; E. O. G. Turville-Petre, Skaldic Poetry, op. cit., p. 85.

27. Ernst A. Kock, Notationes Norrænce, op. cit., § 662 B.

28. Dans Heimskringla, IV, éd. cit., p. 169; Skjaldedigtning, B, I, éd. cit., p. 242.

29. Ordbog over det norrøne prosasprog. A Dictionary of Old Norse Prose, Copenhague, Den arnamagnæanske kommission, I, 1995, s.v. austmaðr.

30. Judith Jesch, « Sigvatr Pórðarson, Erfidrápa Óláfs helga 15 », éd. cit., p. 683.

31. Finnur Jónsson, Skjaldedigtning, B, I, éd. cit., p. 242, qui traduit par : kampen i østen (Norge).

32. Finnur Jónsson, Heimskringla, IV, éd. cit., p. 169 : østfra.

33. Ernst A. Kock, Notationes Norrænce, op. cit., § 662 .

34. Alison Finlay, dans Snorri Sturluson, Heimskringla, volume II : Óláfr Haraldsson (the Saint). Translated by Alison Finlay and Anthony Faulkes, Londres, Viking Society for Northern Research, 2014, p. 256.

35. E. O. G. Turville-Petre, Skaldic Poetry, éd. cit., p. 85.

36. Ordbog over det norrøne prosasprog, I, op. cit., s.v. atburðr, sens 1 : handelse, begivenhed (ofte uventet voldsom begivenhed, ulykke) \| occurrence, event (often an unexpected violent event, accident), voir aussi le sens 2 : (spec. om overnaturlig begivenhed $\|$ spec. of a supernatural event).

37. Finnur Jónsson, Lexicon poeticum, op. cit., p. 20. 
C'est indéniablement sous cette acception que Snorri Sturluson l'a entendu, comme le montre le passage en prose qui suit la citation de la présente strophe au chapitre CCXXVII de l'Óláfs saga ins helga : l'auteur y décrit les conséquences d'ordre pratique qu'aurait eues sur le déroulement du combat la tombée soudaine de l'obscurité peu après le début de la bataille de Stiklestad ${ }^{38}$ : Váru pessir atburðir margir jafnsnimma eða sumir litlu fyrr eða siðar ${ }^{39}$.

Il en résulte que la phrase Frák atburð orrostu doit être traduite au mieux par : « J'ai appris l'événement de la bataille [...]» (sous-entendu : «l'événement [qui survint au cours] de la bataille »), comme le proposait déjà Finnur Jónsson ${ }^{40}$.

Par « événement de la bataille (atburðr orrostu) », Sigvat a manifestement entendu le phénomène naturel qu'il s'est attaché à décrire dans la présente strophe - l'éclipse solaire ${ }^{41}$, si bien que cette déclaration constitue un témoignage d'une importance capitale : selon le scalde islandais, qui se fonde sur les informations qu'il a dû recueillir au retour d'un pèlerinage à Rome, ce fut bel et bien au cours de la bataille de Stiklestad que l'obscurité tomba subitement, et non pas à un moment ultérieur, un autre jour, qui serait différent de celui de la mort d'Olaf Fils Harald, comme l'envisageaient plusieurs exégètes qui voulaient dissocier les deux événements ${ }^{42}$.

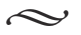

À la suite de ces explications philologiques, le directeur d'études s'est longuement arrêté sur la description de l'éclipse elle-même, en soulignant tout d'abord qu'au sein de chacune des deux parties de la strophe, Sigvat a mis en évidence - comme dans un diptyque - l'une des caractéristiques principales du phénomène astronomique : d'un côté la chute de la température, de l'autre l'absence de clarté ${ }^{43}$. Cette mise en parallèle, à la fois sobre et objective, des deux aspects essentiels d'une éclipse solaire a été rehaussée par la place que le scalde a choisie pour chacun des deux termes qui lui servent à caractériser la tombée de l'obscurité le jour de la bataille : le neutre $u n d r$ (merveille, prodige) vient tout au début du premier vers de la première demi-strophe, tandis que le dernier vers de la seconde demi-strophe s'achève sur le féminin furða. Avec le premier d'entre eux, le scalde se fait l'écho de l'opinion générale qui prévalut

38. Heimskringla, II, éd. Bjarni Aðalbjarnarson, p. 383, cf. Saga Óláfs konungs hins helga, éd. Johnsen et Jón Helgason, p. 573 (chapitre CCXXv).

39. Voir aussi le début du chapitre CCXv (Heimskringla, II, éd. Bjarni Aðalbjarnarson, p. 369) au sujet de l'arrivée d'un champion du nom d'Arnljótr gellini qui voulait se joindre aux forces d'Olaf Fils Harald.

40. Heimskringla, IV, éd. cit., p. 169 : «jeg har hørt om denne tildragelse under kampen [...]», cf. Skjaldedigtning, B, I, éd. cit., p. 242. Voir aussi la traduction de Judith Jesch (« Sigvatr Pórðarson, Erfidrápa Óláfs helga 15 », éd. cit., p. 682) : «I heard of the event at the battle [...]. »

41. Ce point est bien marqué par Barði Guðmundsson, « Dagsetning Stiklastaðaorustu », art. cit., p. 108; Id., « Omkring Stiklestadslaget », art. cit., p. 152; voir aussi Bjarni Aðalbjarnarson, « Formáli », dans Heimskringla, II, éd. cit., p. XCIV.

42. Par exemple J. D. Landmark, Solmørket over Stiklestad, op. cit., p. 13; Id., "Solmørket i 1030 og slaget på Stiklestad », dans Det Kongelige Norske Videnskabers Selskabs Forhandlinger, III, 1930, 27 , Nidaros, 1931, p. 110; Knut Liestøl, « Når stod slaget på Stiklestad? », Maal og Minne, 1932, p. 17, cf. Id., Saga og folkeminne, Oslo, Norlis, 1941, p. 76.

43. Barði Guðmundsson, « Dagsetning Stiklastaðaorustu », art. cit., p. 108-109; Id., « Omkring Stiklestadslaget », art. cit., p. 152-153; Bjarni Aðalbjarnarson, « Formáli », dans Heimskringla, II, éd. cit., p. XCII. 
au sujet de l'événement : Undr láta pat ýtar (« les hommes déclarent... ») eigi smátt, tandis qu'avec le second Sigvat livre manifestement sa propre interprétation de ce phénomène, qu'il relie au destin même de son ami le roi Olaf Fils Harald : Drjúg varð á pví doegri ... konungs furða. Placé qu'il est à la chute de la strophe, en formant un couple avec le mot $u n d r$, le substantif furða revêt dès lors une importance d'autant plus grande qu'il paraît exprimer le sentiment profond du scalde sur la signification qu'il accorda à cette merveille ou à ce prodige (undr). Mais quelle est ici l'acception du mot furða? Et que faut-il entendre par l'expression konungs furða?

D'usage courant en vieux norrois pour désigner l'étonnement, la surprise, la stupéfaction voire la stupeur ${ }^{44}$, le féminin furða signifie d'abord « présage, signe (annonciateur) », en accord avec son étymologie probable : *for-, *fur-riðōn (« qui chevauche en avant, qui va en avant $\left.{ }^{45} »\right)$, et c'est certainement ce sens qu'il convient de retenir ici, de préférence à des acceptions telles que Schrecknis ${ }^{46}$, under $^{47}$ ou mirakel $^{48}$.

La notion de « présage », de « signe (annonciateur) », sur laquelle reposent à juste titre nombre de traductions des vers de Sigvat ${ }^{49}$, demande cependant à être précisée, à la lumière de deux épisodes des Íslendingasögur dans lesquels les mots undr et furða forment un couple, comme dans la présente strophe ${ }^{50}$.

Le premier d'entre eux est relaté au chapitre LI de l'Eyrbyggja saga : un jour d'automne, par un beau temps sec, toute la maisonnée du domaine de Fróðá (sur la côte nord de la péninsule de Snæfellsnes) était occupée aux travaux de la fenaison lorsqu'une panne de nuages noirs surgit subitement dans un ciel serein et se dirigea

44. Voir p. ex. Johan Fritzner, Ordbog over Det gamle norske Sprog, I, 1886, p. 505, s.v.; on sait que, sous la forme du cas oblique furðu, ce mot est volontiers placé devant un adjectif ou un adverbe pour marquer l'intensité voire la démesure, tournure que l'islandais moderne a conservée, cf. Sigfús Blöndal, Islandsk-dansk Ordbog. Íslensk-dönsk orðabók, I-II, Reykjavik, 1920-1924, p. 229, s.v.; Mörður Árnason et al., Íslensk orðabók, Reykjavik, Edda, 2000, p. 404, s.v. - Exceptionnellement il a servi à former des substantifs composés, p.ex. furðuhogg (dans la Karlamagnús saga, cf. Ordbog over det norrøne prosasprog, s.v. [= onp.ku.dk]) et les énigmatiques Furðustrandir sur le littoral de l'Amérique du Nord, cf. Richard Perkins, « The Furðustrandir of Eiriks saga rauða », Mediaeval Scandinavia, IX, 1976, p. 51-98.

45. Alf Torp, « Gamalnorsk ordavleiding », dans Marius Hægstad et Alf Torp, Gamalnorsk Ordbok med nynorsk tyding, Kristiania, Det Norske Samlaget, 1909, p. XL (repris dans Id., Gamalnorsk ordavleiding. Nyutgåva med rättelser och register ombesörjd av Gösta Holm, Lund, Gleerups [Scripta Minora Regiae Societatis Humaniorum Litterarum Lundensis, 1973-1974 : 2], 1974, p. 15); Id., Nynorsk etymologisk Ordbok, Kristiania, Aschehoug, 1919, p. 140; Finnur Jónsson, Lexicon poeticum, op. cit., p. 159; Jan de Vries, Altnordisches etymologisches Wörterbuch. Zweite verbesserte Auflage, Leyde, Brill, 1962, p. 147; Ásgeir Blöndal Magnússon, Íslensk orðsifjabók, op. cit., p. 217.

46. Konrad Maurer, Die Bekehrung des Norwegischen Stammes zum Christenthume, in ihrem geschichtlichen Verlaufe quellenmäßig geschildert, II, Munich, Christian Kaiser, 1856, p. 535.

47. Halvdan Koht, « Solmyrke i Stiklestad-slage », art. cit., p. 37.

48. Ernst A. Kock, Notationes Norronce, op. cit., §662.

49. Voir p. ex. Jón Ólafsson (frá Svefneyjum), dans Heimskringla edr Noregs Konunga-Sögor, af Snorra Sturlusyni. Snorre Sturlesons Norske Kongers Historie. Historia Regum Norvegicorum conscripta a Snorrio Sturla filio [...], édition Gerhard Schøning, Copenhague, II, 1778, p. 368 : Tegn; Sveinbjörn Egilsson, dans Historia regis Olavi Sancti. Opera et studio Sveinbjörnis Egilssonii, Copenhague (Scripta historica Islandorum, IV-V), II, 1833, p. 85 : portentum; Finnur Jónsson, Skjaldedigtning, B, I, p. 242 : jcertegn; J. Jesch, « Sigvatr Pórðarson, Erfidrápa Óláfs helga 15 », éd. cit., p. 682 : portent.

50. Cf. E.O.G. Turville-Petre, Skaldic Poetry, op. cit., p. 85. 
rapidement vers Fróðá : lorsque ces nuages passèrent au-dessus de la ferme, une obscurité totale se fit et il plut d'abondance, si bien que tout le foin qui n'avait pas encore été ratissé fut détrempé. Quand le ciel s'éclaircit à nouveau, on constata que c'était une pluie de sang qui était tombée. Interrogée sur la signification de ce prodige (undr) et sur ce qu'il annonçait ${ }^{51}$, une femme du nom de Thorgunna (v.isl. Dórgunna) répondit tout d'abord qu'elle ne le savait pas, puis elle ajouta ${ }^{52}$ :

...en pat pykkir mér líkligast [...], at petta muni furða nǫkkurs pess manns, er hér er.

Soit dans une traduction littérale :

...mais il me semble que le plus vraisemblable est [...] que cela doit être le présage de la mort de quelqu'un qui se trouve ici.

De fait, l'un des membres de la maisonnée - Thorgunna en personne - tomba aussitôt malade, dut s'aliter et mourut peu de temps après. Dans la logique du récit, la mort de cette femme paraît être la conséquence directe de la «pluie de sang ${ }^{53}$ », mais l'interprétation qu'elle avait elle-même donnée du prodige n'en éclaire pas moins la valeur du mot furða d'une manière décisive : suivi d'un génitif d'objet, il prend l'acception particulière todesankündigung ${ }^{54}$, feigðarboði ${ }^{55}$, soit : " présage de mort », « annonce d'une mort (imminente)».

C'est la même acception du mot furða que l'on relève également dans un curieux passage de la Heiðarvíga saga : au chapitre Xxvi, l'auteur relate que, mécontent de la nourriture qui lui était présentée de bon matin, un homme du nom de Thorbiorn (v.isl. Dorbjorn) s'en prit violemment à la maîtresse de maison qui venait de le servir à table, en déclarant que ce plat ne contenait que du sang. Dans la réplique qu'elle adressa à Thorbiorn, la femme lui fit comprendre qu'il avait été victime d'une illusion des sens, mais que ce prodige (undr) signifiait qu'il séjournerait « bientôt dans le séjour des morts (brátt i helju) », avant d'ajouter ${ }^{56}$ : « et cela doit certainement être l'annonce de ta mort prochaine (bín furða) ». De fait, Thorbiorn périt au cours d'une bataille qui se déroula un peu plus tard et qui a donné son nom à cette œuvre islandaise du tout début du XIII ${ }^{\text {e }}$ siècle $^{57}$.

51. Eyrbyggja saga, éd. Einar Ól. Sveinsson, Reykjavik, Hið íslenzka fornritafélag (Íslenzk fornrit, IV), 1935, p. 140 : Póroddr spurði, hvat Pórgunna cetlar, at undr petta muni benda; au lieu du verbe benda, « indiquer, montrer », le manuscrit sur parchemin AM $162 \mathrm{E} \mathrm{fol} \mathrm{et,} \mathrm{avec} \mathrm{lui,} \mathrm{trois} \mathrm{autres} \mathrm{manuscrits} \mathrm{(cf.}$ Eyrbyggja saga. The Vellum Tradition, éd. Forrest S. Scott, Copenhague [Editiones Arnamagnæanæ, Series A, XVIII], p. 238-239) présentent la leçon fyrirboða, « annoncer, présager, augurer », qui est plus explicite encore.

52. Eyrbyggja saga, éd. Einar Ól. Sveinsson, p. 140, cf. Eyrbyggja saga, éd. Scott, p. 239, avec la leçon furða nokkurs manns pess, er hér er viðriðinn (« le présage de la mort de quelqu'un qui est ici concerné/ impliqué »).

53. Cf. Kjartan G. Ottósson, Fróðarundur i Eyrbyggju, Reykjavik, Bókaútgáfa Menningarsjóðs (Studia Islandica. Íslensk fræði, XLII), 1983, p. 62.

54. Hugo Gering, dans l'annotation de son édition de l'Eyrbyggja saga, Halle, Niemeyer (Altnordische Saga-Bibliothek, VI), 1897, p. 185.

55. Einar Ól. Sveinsson, dans l'annotation de son édition de l'Eyrbyggja saga, 1935, p. 140.

56. Heiðarvíga saga, édition Sigurður Nordal et Guðni Jónsson, dans Borgfirðinga sogur [...], Reykjavik, Hið íslenzka fornritafélag (Íslenzk fornrit, III), ${ }^{2} 1956$, p. 289.

57. Elle est relatée au chapitre XXX, éd. cit., p. $301 s q$. 
Employé avec un pronom possessif (comme dans ce dernier exemple) ou avec un génitif d'objet (comme dans l'Eyrbyggja saga), le mot furða doit non seulement posséder la signification de base « présage », «omen », mais désigner plus précisément le fait qu'un personnage était considéré comme feigr, c'est-à-dire " marqué par la mort», " voué à une mort prochaine ${ }^{58}$ ». Aussi l'acception spécifique « annonce d'une mort imminente » a-t-elle été légitimement retenue par plusieurs lexicographes ${ }^{59}$ de même que par les principaux éditeurs des poèmes scaldiques ${ }^{60}$ et de la Heimskringla ${ }^{61}$.

Comme le montre le parallélisme avec la déclaration attribuée à Thorgunna dans l'Eyrbyggja saga, le syntagme konungs furða, qui constitue la magnifique chute de la strophe de Sigvat, ne peut pas être traduit par kongs-under ${ }^{62}$, ni par konungamiraklet $^{63}$ ou that miracle of the king ${ }^{64}$ : nous ne sommes pas ici en présence d'un génitif subjectif qui indiquerait que l'action aurait été accomplie par la personne désignée,

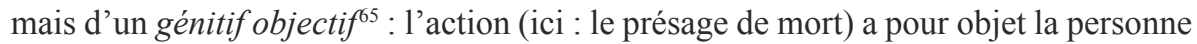
dont il est question, en l'occurrence le roi.

Il en résulte que le scalde considéra manifestement que l'éclipse solaire avait été en elle-même un signe annonciateur de l'événement capital qui survint au cours de la bataille de Stiklestad : la mort du roi Olaf Fils Harald. L'interprétation de ce phénomène astronomique par Sigvat procède ainsi de la croyance aux présages, conviction

58. Si la lecture du vers 3 de la strophe XXVIII des Atlamál in grœnlenzku ne faisait pas difficulté, ce serait vraisemblablement cette acception qui devrait être retenue ici, mais l'on sait que le Codex regius des poèmes eddiques présente à cet endroit une graphie ambivalente : elle peut s'interpréter soit par le substantif for suivi de l'adverbe pó (cf. Eddukvaeði, II : Hetjukvaeði, éd. Jónas Kristjánsson et Vésteinn Ólason, Reykjavik, Hið íslenzka fornritafélag [Íslenzk fornrit], 2014, p. 387) soit par le cas oblique du mot furða, comme cela a été proposé avec de bons arguments par Theodor Hjelmqvist (« Några anmärkningar till Atlamál », Arkiv för nordisk filologi, XI, 1894, p. 107-112), suivi notamment par Hugo Gering et B. Sijmons, Kommentar zu den Liedern der Edda, II : Heldenlieder, Halle, 1931 (Germanistische Handbibliothek, VII, 3, 2), p. 376; Ursula Dronke, The Poetic Edda, I, Heroic Poems, Oxford, Clarendon, 1969, p. 122; Klaus von See et al., Kommentar zu den Liedern der Edda, VII : Heldenlieder, Heidelberg, Universitätsverlag Winter, 2012, p. 490-491.

59. Erik Jonsson, Oldnordisk Ordbog ved det Kongelige Nordiske Oldskrift-Selskab, Copenhague, 1863, p. 154, s.v. furða : «1) Tegn, Varsel. - Spec. Varsel for ens ncerforestaaende Död [...]. »; Johan Fritzner, Ordbog over Det gamle norske Sprog, I, Kristiania, 1886, p. 505, s.v., sens 2 : « Varsel, Forbud om en tilkommende Begivenhed, lat. portentum, omen; [...] ogsaa om ens $(e-s)$ Død [...]»; Christopher Sanders dans Ordbog over det norrøne prosasprog, s.v. furða [= onp.ku.dk], sens 1 : « [e-rs] [e-s / fyrir e-u] [e-m] omen (esp. of sby's imminent death) ».

60. Notamment Konráð Gíslason, Udvalg af Oldnordiske Skjaldekvad, éd. cit., p. 185, qui renvoie à Fritzner, Ordbog, s.v. furða, sens 2 (voir ci-dessus); E.O.G. Turville-Petre, Skaldic Poetry, éd. cit., p. 85 : « Great was the portent of the King's death [...]. »

61. Par exemple Finnur Jónsson, dans Heimskringla, IV, éd. cit., p. 169 : « det jærtegn, som angik kongen (dødsvarslet) »; Bjarni Aðalbjarnarson, Heimskringla, II, éd. cit., p. 383, dans l'annotation : « furða : feigðarboði ».

62. Halvdan Koht, « Solmyrke i Stiklestad-slage », art. cit., p. 37.

63. Ernst A. Kock, Notationes Norronce, op. cit., §662.

64. Martin Chase, Einarr Skúlason's Geisli. A Critical Edition, Toronto, University of Toronto Press (Toronto Old Norse and Icelandic Studies, I), 2005, p. 140.

65. Cf. Finnur Jónsson, Heimskringla, IV, éd. cit., p. 169; sur la distinction genitivus subjectivus et genitivus objectivus en vieux norrois, voir notamment M. Nygaard, Norrøn syntax, Kristiania, Aschehoug, 1905, § 124-125 (p. 130-133); Jan Terje Faarlund, The Syntax of Old Norse. With a survey of the inflectional morphology and a complete bibliography, Oxford, Oxford University Press, 2004, p. 59-67. 
qui était profondément ancrée dans les mentalités scandinaves, comme en porte amplement témoignage la littérature norroise ${ }^{66}$.

En conclusion de cette étude, il a été souligné que la strophe de Sigvat est dépourvue de toute connotation d'ordre hagiographique, de tout rapprochement explicite ou implicite avec la venue des ténèbres au moment de la Crucifixion ${ }^{67}$, en sorte qu'il paraît improbable que le scalde ait pu être abusé par un récit fallacieux que des clercs auraient construit au sujet du dernier combat d'Olaf Fils Harald ${ }^{68}$.

Dans sa sobriété, dans son réalisme, dans son absence d'analogie avec la Passio du Christ, la description par Sigvat de l'éclipse solaire lors de la bataille de Stiklestad tranche fortement sur l'évocation qu'en donna Einar Fils Skuli (v.isl. Einarr Skúlason) quelque cent vingt ans plus tard. Lorsqu'il célébra le roi saint Olaf dans le poème Geisli, qu'il récita au sein de la cathédrale de Nidaros, vraisemblablement en 1153, le jour même de la célébration de la Saint-Olaf ${ }^{69}$, ce scalde islandais, qui était de formation cléricale, démarqua son prédécesseur en rappelant les circonstances de la fin du roi de Norvège ${ }^{70}$. À la strophe XIX de ce poème ${ }^{71}$, Einar reprit plusieurs termes que Sigvat avait employés au sujet de l'éclipse solaire (en particulier le mot poétique roðull et la forme verbale náðit), mais il en fit non seulement un événement concomitant de la mort d'Olaf, qu'il rapprocha ainsi de celle du Christ (v.isl. dauði harra hauðrtjalda), mais une manifestation des signes de Dieu (grundar salvorðr sýndi sín tọkn).

66. Voir notamment Walther Gehl, Der germanische Schicksalsglaube, Berlin, Junker und Dünnhaupt, 1939, p. 47 sq. et 157 sq.

67. Comme l'avait bien observé Barði Guðmundsson, « Dagsetning Stiklastaðaorustu », art. cit., p. 110111 ; Id., « Omkring Stiklestadslaget », art. cit., p. 153.

68. Comme l'envisageait Finnur Jónsson, Heimskringla, IV, éd. cit., p. 169 : « det er noget, de gjestlige har lavet og som Sigvatr har trot ». Mais le seul argument avancé à l'appui de cette assertion n'est pas recevable : le fait que Sigvatr déclara expressément qu'il tenait d'autrui sa connaissance des événements n'implique en aucune manière que ce fut auprès d'affabulateurs (qu'ils aient été clercs ou non) que le scalde apprit la tombée subite de l'obscurité lors de la bataille de Stiklestad. La déclaration frák («j'appris / j'ai appris ») est relevée dans nombre de strophes du même scalde, que ce soit dans l'Erfidrápa Óláfs helga (strophes VII, XII, XVIII ) ou dans d'autres œuvres, et c'est là un trait narratif très fréquent chez les scaldes (voir p. ex. Carol J. Clover, « Skaldic Sensibility », Arkiv för nordisk filologi, XCIII, 1978, p. 64).

69. Cf. Martin Chase, Einarr Skúlason's Geisli, éd. cit., p. 9-10; Id., dans Poetry on Christian Subjects. Part 1 : The Twelfth and Thirteenth Centuries. Edited by Margaret Clunies Ross, Turnhout, Brepols (Skaldic Poetry of the Scandinavian Middle Ages), 2007, p. 5-6.

70. Einarr fait explicitement référence à Sigvat Fils Thord (ainsi qu'au scalde Ottar le Noir [v.isl. Óttarr svarti]) à la strophe XII du même poème (édition Chase, 2005, p. 62, cf. Id., éd. 2007, p. 17).

71. Édition Chase (2005, p. 69, cf. Id., éd. 2007, p. 22) : Náðit bjartr, pás beiðir / baugskjalda lauk aldri / — sýndi salvorðr grundar / sín tọkn — rǫðull skina. / Fyrr vas hitt, at harra / hauðrtjalda brá dauða / happ- (nýtask mér) - maetu / (máltól) skini sólar. Soit dans la traduction anglaise proposée par l'éditeur (2005, p. 69) : The bright sun was not permitted to shine then, when the desirer of the ring-shield lost his life; the guardian of the hall of earth showed his signs. It was previously that the blessing-rich shining of the sun ceased at the death of the king of earth's roof; speech-tools are of use to me. 
Si ces deux innovations importantes influencèrent fortement le récit de la mort d'Olaf Fils Harald par l'auteur de l'Histoire légendaire de saint Olaf ${ }^{72}$, force est de constater que Snorri Sturluson ne les reprit pas à son compte lorsqu'il composa l'Óláfs saga ins helga: fondée principalement sur l'Erfidrápa Óláfs helga, sa relation de la bataille de Stiklestad n'est pas marquée au sceau de l'hagiographie de saint Olaf, et la description que l'historien islandais nous a laissée de l'éclipse solaire procède pour l'essentiel - de la strophe de Sigvatr Pórðarson.

72. Olafs saga hins helga. Die "Legendarische Saga” über Olaf den Heiligen (Hs. Delagard. saml. nr. 8I) herausgegeben und übersetzt von Anne Heinrichs, Doris Janshen, Elke Radicke, Hartmut Röhn, Heidelberg, Winter, 1982, chapitre LXXXII, p. 196. 